\title{
Termografía infrarroja aplicada en cúpulas históricas: identificación y análisis de sistemas constructivos
}

\section{Infrared thermography applied to historical domes: identification and analysis of building systems}

\author{
J. C. Pérez-Sánchez ${ }^{(*)}, \underline{\text { B. Piedecausa-García }}{ }^{(*)}$
}

\section{RESUMEN}

El uso específico de la termografía infrarroja como técnica no destructiva permite el estudio de sistemas constructivos en edificios históricos (caracterización de materiales, disposición constructiva o identificación de elementos originales). Así, se muestra una aplicación práctica en templos en la provincia de Alicante construidos entre finales del siglo xvi y principios del XIX, donde se analiza la complementariedad de las imágenes termográficas de 140 cúpulas (junto con datos recopilados in situ, dibujos originales y levantamiento de planos) como herramienta de estudio en fases de análisis previas a una restauración.

En conclusión, la investigación detalla una aplicación termográfica al estudio de distintos aspectos como el reconocimiento de materiales empleados (90,71 \% ladrillo macizo, 6,43 \% ladrillo hueco y 2,86 \% piedra), variaciones de espesor interior y exterior (75,71 \% perfil apuntado, 17,86 \% perfil semiesférico y 6,43\% perfil rebajado), caracterización de grietas/fisuras (estado de conservación) e identificación de cúpulas originales (96,43\%) o restauradas (3,57 \%).

Palabras clave: Termografía infrarroja; cúpula; evaluación constructiva; método no destructivo; edificios históricos; conservación del patrimonio.

\section{ABSTRACT}

The specific use of infrared thermography as a non-destructive technique allows the study of constructive systems in historic buildings (characterization of materials, construction layers and identification of original / restored elements). Thus, a practical application is shown in temples built between the late seventeenth and the early nineteenth century in the province of Alicante, where complementarity of thermographic images of 140 domes is analysed (along with data collected in situ, original drawings and draw up plans) as a research tool in analysis phases prior to a restoration.

In conclusion, research shows how thermography is applicable to the study of different aspects such as the recognition of materials used ( $90.71 \%$ solid brick, $6.43 \%$ hollow brick and $2.86 \%$ stone), thickness variations (75.71\% pointed shape, $17.86 \%$ hemispherical shape and $6.43 \%$ low shape), characterization of cracks / fissures (conservation conditions) and identification of original ( $96.43 \%$ ) o restored domes (3.57\%).

Keywords: Infrared thermography; dome; constructive examination; non-destructive method; historical buildings; heritage conservation.

(*) Universidad de Alicante (España).

Persona de contacto/Corresponding author: piedecausa@ua.es (B. Piedecausa-García)

Cómo citar este artículo/Citation: Pérez-Sánchez, J. C., Piedecausa-García, B. (2016). Termografía infrarroja aplicada en cúpulas históricas: identificación y análisis de sistemas constructivos. Informes de la Construcción, 68(541): e129, doi: http://dx.doi.org/10.3989/ ic.14.133.

Licencia / License: Salvo indicación contraria, todos los contenidos de la edición electrónica de Informes de la Construcción se distribuyen bajo una licencia de uso y distribución Creative Commons Reconocimiento no Comercial 3.o. España (cc-by-nc). 


\section{INTRODUCCIÓN}

Las construcciones históricas, que forman parte del patrimonio arquitectónico y cultural de una zona geográfica determinada, habitualmente presentan singularidades propias respecto a las edificaciones actuales ya sea tanto a nivel puramente constructivo como a nivel conceptual. Así, la provincia de Alicante recoge una gran cantidad de templos religiosos con importante valor arquitectónico, construidos en su mayoría durante el siglo xviII, que hoy día requieren de un análisis constructivo profundo y riguroso donde basar propuestas de rehabilitación y/o recuperación de aquellos elementos patrimoniales deteriorados por el paso del tiempo.

El conocimiento del estado de conservación y los sistemas constructivos empleados en dichos edificios es fundamental para una correcta intervención; sin embargo, la dificultad de análisis de muchos de sus elementos es elevada debido a la escasa información previa disponible (proyecto de construcción, bibliografía histórica, documentación de archivos particulares, etc.) y el desconocimiento de los materiales o las técnicas empleadas. En el caso concreto de la provincia de Alicante, muchos archivos parroquiales fueron destruidos durante la guerra civil, perdiendo una documentación de valor incalculable y la oportunidad de reconstruir hechos históricos de gran importancia; por ello, son escasos los edificios estudiados que conservan sus libros de fábrica (1) y en ellos la información relacionada con la construcción de los templos es mínima.

En este contexto, el presente estudio apuesta por el empleo complementario de técnicas de reconocimiento no destructivas, concretamente la termografía infrarroja, como una herramienta eficaz y significativa para el estudio e identificación de ciertos sistemas constructivos empleados en edificios históricos durante las fases de análisis previas a su restauración.

\section{FUNDAMENTOS DE LA TERMOGRAFIA INFRARROJA}

Los sistemas constructivos que conforman cerramientos en edificación permiten separar determinados espacios, habitualmente uno exterior y otro interior, que se encuentran a distinta temperatura. Teniendo en cuenta las leyes de la termodinámica, entre ambos ambientes se producen fenómenos de transferencia de calor (energía) mediante tres formas básicas: conducción, convección y radiación (2).

Entre esos dos espacios citados, la transferencia de energía hasta el elemento constructivo se produce inicialmente por convección y radiación mientras que, dentro del mismo, se transmite fundamentalmente por conducción en función de su composición (acumulándose cierta energía en su masa térmica) o en menor medida por fenómenos de convección y radiación si existen oquedades (cámaras de aire, ladrillo hueco, etc.); además, cuando se llega al otro ambiente, esa energía se vuelve a transferir de nuevo en forma de convección y radiación. Esta última transmisión de calor por radiación es la captada por la cámara termográfica.

Así, todos los cuerpos transmiten energía en forma de radiación, y puesto que cada objeto se encuentra a una determinada temperatura, emiten cierta radiación térmica considerando que, a mayor temperatura, mayor cantidad de radiación será emitida (3). Dicha radiación es proporcional a la cuarta potencia de la temperatura superficial del objeto, lo que se conoce habitualmente como Ley de Stefan-Boltzmann (4). De este modo, basándose en esta ley, la cámara termográfica traduce los citados niveles de radiación en escalas de temperatura (representadas mediante imágenes térmicas) que son de gran utilidad para identificar, analizar e interpretar los elementos constructivos existentes en cada caso.

También es importante destacar que, al ser una herramienta que proporciona datos en forma de imágenes, la termografía aporta una información muy detallada en los procesos de transferencia de calor si se compara con otros medidores puntuales más clásicos; esta información se complementa con la obtención instantánea y continua de otros datos (temperatura del objeto, emisividad de superficies, temperatura ambiente, rango de temperaturas, etc.) sin necesidad de un contacto directo con el propio objeto y considerando la variable tiempo en el análisis de una manera más precisa que en otras metodologías tradicionales.

Considerando algunas de sus ventajas (rapidez de inspección, distancia respecto al elemento estudiado, uso de radiaciones inocuas, resultados visuales, amplio rango de aplicaciones, etc.) y a pesar de ciertos inconvenientes (heterogeneidad de excitaciones en ciertas medidas, variación de resultados según el mecanismo de transferencia de calor, limitación de detección en zonas sub-superficiales, etc.) (5), la termografía infrarroja se plantea como una técnica no destructiva seria, fiable y precisa como instrumental complementario en el ámbito arquitectónico.

Actualmente, la aplicación cualitativa de la termografía en edificación se extiende fundamentalmente en el ámbito de la inspección (fugas en instalaciones, presencia de humedades, patologías de fachada, puentes térmicos en envolventes, etc.) (6) basándose en la detección de gradientes térmicos anómalos durante el reconocimiento; también existen otras aplicaciones para el estudio específico de materiales de construcción (7) o para la inspección de ciertas tipologías edificatorias (8). No obstante, el uso de esta técnica no está extendido hoy en día para el análisis de sistemas constructivos en edificios históricos (identificación de materiales, presencia de lesiones estructurales, caracterización de sistemas ocultos tras reparaciones no documentadas, etc.), siendo una aplicación de gran interés a desarrollar y que se particulariza para el análisis de cúpulas históricas en el presente estudio.

\section{OBJETIVOS}

El objetivo principal de la investigación es evaluar la aplicación práctica de la termografía infrarroja para el estudio de sistemas constructivos en edificios históricos, posibilitando la caracterización de materiales, el estudio de su disposición constructiva, la identificación de elementos originales/restaurados y su estado de conservación; todo ello mediante el empleo de un método no destructivo y sirviendo como base documental previa para futuras intervenciones arquitectónicas.

Este objetivo se particulariza para el estudio concreto de las cúpulas de ladrillo en templos de la provincia de Alicante, construidas entre finales del siglo xVII y principios del XIX, al ser uno de los elementos más destacados y significativos de la arquitectura religiosa en dicho ámbito por sus características constructivas, su presencia geométrica y su mayor exposición a movimientos estructurales y/o a agentes atmosféricos. 
Así, la investigación planteada pretende examinar las citadas variables en dichas cúpulas utilizando la complementariedad de la termografía como herramienta previa de análisis no destructivo, así como interpretar la fiabilidad de las imágenes obtenidas gracias a un posterior contraste con la documentación específica existente en fuentes documentales y/o con el trabajo de campo propio elaborado para cada templo.

\section{METODOLOGÍA}

La investigación propuesta se fundamenta en una primera fase de estudio sobre la documentación específica existente para cada templo (toma de datos geométricos/termográficos in situ, revisión de fuentes documentales y elaboración de documentación gráfica propia); una segunda fase de relación, análisis y comparativa de los datos individualmente obtenidos en las cúpulas con la documentación del proyecto original o de rehabilitaciones posteriores; $y$, finalmente, el establecimiento de conclusiones sobre la fiabilidad de los datos interpretados mediante imágenes termográficas así como la identificación de aplicaciones específicas como una herramienta no destructiva a emplear en un análisis profundo y singular de sistemas constructivos históricos, particularizado para el caso de la construcción de cúpulas de ladrillo en templos de la provincia de Alicante.

La metodología planteada se basa en una revisión bibliográfica de un primer inventario con los 159 templos (iglesias, ermitas, monasterios y otros edificios religiosos de piedra o ladrillo) existentes en la provincia de Alicante (9). Una vez programadas las visitas a dichos templos, el trabajo de campo se focaliza en la elaboración de termografías interiores y exteriores mediante cámara termográfica TermaCAM P25 de FLIR para el estudio de sus cúpulas de crucero. La documentación termográfica se completa con otra información recabada in situ como croquis a mano alzada acotados (plantas, secciones y perspectivas de las cúpulas mediante distanciómetro laser Leica DISTO, flexómetro y cinta métrica) y fotografías digitales interiores, exteriores y de detalle (mediante cámara réflex digital CANON EOS-450D, objetivos electrónicos SIGMA 10-20 mm, CANON 18-55 mm, CANON 55-200 mm, filtros UV y trípode VELBON). Por otro lado, de manera paralela a la toma de datos, se procede a un análisis bibliográfico de fuentes documentales, tanto de carácter general como específico, en archivos parroquiales (10), archivos municipales (11) y archivos de proyectos de restauración (12) (Figura 1).
Tras un primer estudio de la documentación obtenida, se identifica la existencia de falsas cúpulas dentro de la selección inicial, puesto que 19 de los ejemplos considerados (11,94\%) no pueden ser catalogados realmente como cúpulas. Así, tras su descarte, se establece un conjunto final de 140 templos para el desarrollo del presente estudio.

A continuación, con la información derivada de las termografías, de los datos in situ y de la consulta documental para cada templo concreto, se procede al análisis gráfico y constructivo de los elementos arquitectónicos identificables en las imágenes térmicas; durante dicho proceso, también se utiliza el software FLIR QuickReport (Versión 1.2, 2009) para la mejora del análisis, gestión y calidad gráfica de las imágenes obtenidas.

Finalmente, con la información específica documentada y contrastada para cada uno de los templos, se obtienen conclusiones concretas sobre la utilidad de la termografía en la detección de los sistemas constructivos en dichos edificios históricos y el estado de conservación de sus cúpulas de ladrillo; un procedimiento y metodología que pueden ser extendidos y aplicados al estudio de otras singularidades en cualquier otro tipo de construcciones con carácter patrimonial a nivel nacional o internacional.

Por último, cabe destacar que la utilización de la termografía infrarroja descrita en el presente artículo permitió acotar la selección final de 38 cúpulas de ladrillo originales en los cruceros de iglesias o catedrales construidas desde finales del siglo XVII hasta principios del XIX, para un estudio históricoconstructivo más pormenorizado en 35 localidades de la provincia de Alicante (13).

\section{RESULTADOS}

\subsection{Identificación de materiales empleados: ladrillo hueco o macizo}

El ladrillo macizo fue utilizado de manera habitual en las cúpulas de los templos alicantinos desde finales del siglo xvir; posteriormente, a partir del segundo tercio del siglo XIX, otros nuevos materiales fueron empleados (como el ladrillo hueco, con o sin la ayuda de estructuras auxiliares de acero) tanto para la construcción de nuevas cúpulas como para la restauración total o parcial de aquellas ya existentes que dejaron, por tanto, de ser originales.
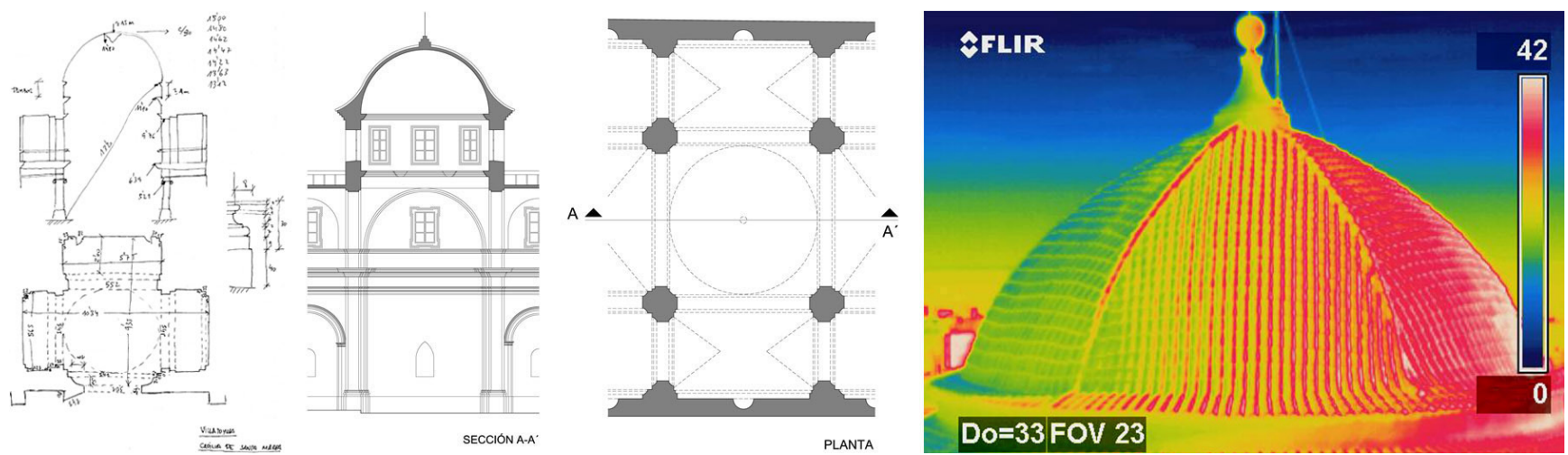

Figura 1. Tipos de documentación utilizada para la investigación. Imagen primera. Croquis de sección de Iglesia de San José en Villafranqueza. Imagen segunda y tercera. Sección y planta a escala de la cúpula de crucero en la Iglesia de San Felipe Neri en Crevillente. Imagen cuarta. Termografía exterior de la cúpula de crucero en la Iglesia de la Virgen de Belén en Crevillente. (Fuente propia). 
Debido a que, en muchos casos, no se seguían las normas hasta entonces establecidas por los tratados de construcción y no existía documentación gráfica o histórica de las modificaciones llevadas a cabo en cada caso, la correcta catalogación de los materiales cerámicos originalmente empleados en las cúpulas se presenta harto difícil, cuando no imposible, sin la realización de un ensayo destructivo (cata) que deteriore el elemento analizado. Teniendo en cuenta este contexto, las termografías del presente estudio han permitido la identificación del material de construcción utilizado en cada templo ya que, contrastando los resultados de las imágenes con la fecha del edificio, el uso de ladrillo hueco delata en muchos casos el empleo de un material inexistente en la época inicial y, por tanto, aportado a posteriori. No obstante, llegar a esta conclusión no resulta algo inmediato, siendo necesario interpretar correctamente las termografías y compararlas con las fuentes documentales existentes con el fin de plantear posibles hipótesis constructivas durante el proceso.

En concreto, el estudio de la Iglesia de San Felipe Neri en Crevillente (s. XviII) muestra una aplicación práctica donde las imágenes termográficas complementan necesariamente al análisis constructivo para la determinación del nivel de restauración de dicha cúpula con ladrillo hueco, al mostrar un perfil térmico que no concuerda con su época de construcción (Figura 2). De este modo, se obtiene una imagen singular con unas líneas dispuestas de forma radial mostrando una clara diferencia entre elementos con distintas densidades a diferentes temperaturas, donde los elementos constructivos con temperatura más baja corresponden a materiales más densos, y los elementos con temperatura más alta son aquellos de menor densidad.

Debido al diferente soleamiento existente durante la toma de la imagen termográfica, también se observa un área más caliente en su parte inferior, correspondiendo con una incidencia directa del sol. Al existir una mayor radiación térmica, las zonas más densas muestran diferente transmisión y, por tanto, diferente temperatura (manifestando la existencia de materiales con distinta densidad). En la zona más fría, al no existir esta diferencia térmica, las líneas más densas escasamente son apreciables en la imagen.

Con todo ello, gracias a las imágenes termográficas se determina que el nivel de restauración del elemento es completo, lo que se ve corroborado por la información obtenida sobre el derrumbe en la linterna de la cúpula original en 1947, que ocasionó daños en distintos elementos y motivó una reconstrucción total de la cúpula con dos hojas de rasilla, generando un perfil semicircular y sin linterna.

En un principio, esas líneas podrían haber correspondido a una estructura metálica auxiliar en forma de jaula semiesférica, pudiendo ser una cúpula restaurada por completo. Este es el caso de la Iglesia de Santa María de Elche, donde la cúpula de piedra fue sustituida completamente en 1905 por una nueva de ladrillo con un armazón de hierro de 14,54 m de diámetro (ver apartado 5.2). Sin embargo, el diámetro de la cúpula de San Felipe Neri es 6,47 m (menos de la mitad que en Santa María de Elche), lo que hace inviable la hipótesis de utilización de una estructura metálica auxiliar para su restauración.

Tras descartar esta suposición, la toma de datos in situ proporcionó una evidencia de la no originalidad de la citada cúpula en Crevillente, ya que la flecha interior $(3,24 \mathrm{~m})$ es la mitad del diámetro, dando lugar a un perfil interior semiesférico (flecha/diámetro $=0,5$ ) distinto al característico de los cruceros de la zona, donde predomina mayoritariamente el perfil peraltado. Por último, la consulta de fuentes escritas sobre el templo y el análisis de los datos obtenidos in situ confirmaron que la cúpula fue originariamente construida con perfil peraltado y linterna, derrumbándose a principios del siglo xx y restaurándose posteriormente con ladrillo hueco, generando un nuevo perfil semicircular.

En definitiva, y teniendo en cuenta estas consideraciones, es posible concluir que las líneas concéntricas de menor temperatura marcadas en la termografía coinciden con los caballetes de teja existentes en la cubierta de la cúpula, es decir, se corresponden con una cúpula construida con ladrillo hueco (ya que muestra una menor densidad que una construida con ladrillo macizo) en la que se aprecian los caballetes a su través. Cabe destacar que, en la mayoría de las termografías realizadas en los templos del presente estudio, no se detectan los caballetes de la cubierta, pudiendo concluirse que son originales (o intervenidas puntualmente) y están construidas con ladrillo macizo.

\subsection{Distinción de variaciones de espesor: diferencias entre perfil interior y exterior}

En la mayor parte de los templos seleccionados para el presente estudio (75,71 \% de los casos), las termografías muestran distribuciones de temperaturas donde la zona central,
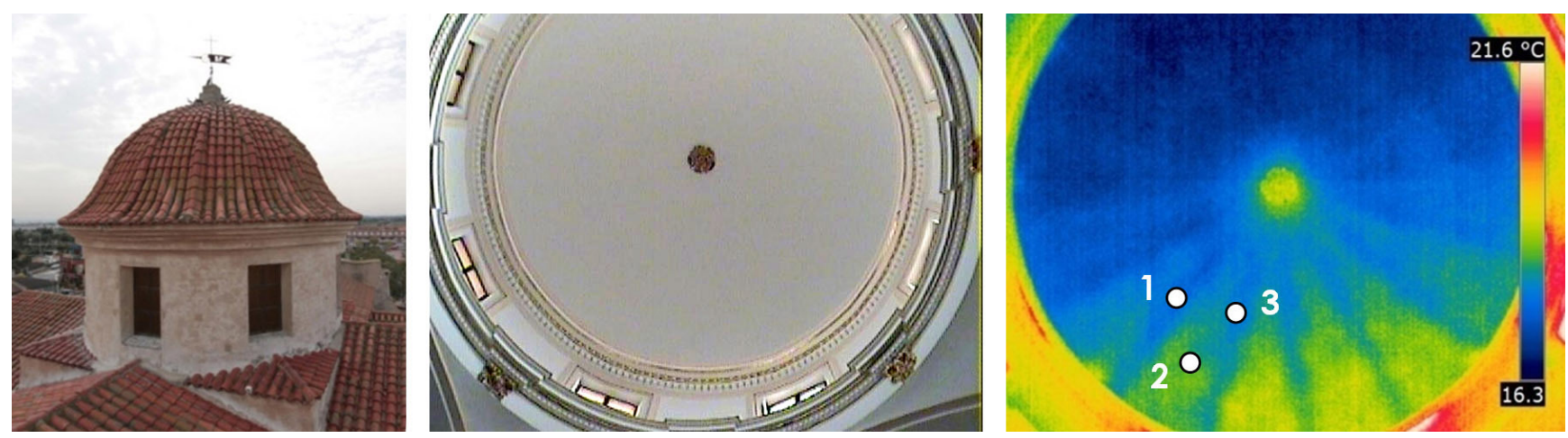

Figura 2. Cúpula de crucero en la Iglesia de San Felipe Neri en Crevillente. Imagen izquierda. Vista exterior de la cúpula. Imagen central. Vista interior de la cúpula. Imagen derecha. Termografía de la cúpula de crucero con identificación de temperaturas destacadas T 1 (17,7 ${ }^{\circ} \mathrm{C}$ ), $\mathrm{T}^{\mathrm{a}} 2\left(18,4^{\circ} \mathrm{C}\right)$ y $^{\mathrm{a}} 3\left(17,7^{\circ} \mathrm{C}\right)$. (Fuente propia). 
que corresponde con la parte más alta de la cúpula (aproximadamente de $1 / 3$ del radio), presenta una menor transmisión de temperatura y, por tanto, corresponde a un elemento de mayor densidad. Esta disposición contrasta con el perímetro tanto de la zona intermedia como la más baja de la cúpula (aproximadamente de 2/3 del radio) con mayor transmisión de temperatura y, por tanto, correspondiendo a un elemento con menor densidad; esa diferenciación incluso es apreciable con una incidencia solar directa.

Dicho fenómeno es debido a que las cúpulas estudiadas presentan un contorno interno diferente al externo (correspondiente a perfiles apuntados), con peralte exterior mayor que el interior; esto se traduce en una variación del espesor en la cáscara (diferentes densidades) que se ve reflejada en zonas de mayor y menor transmisión de temperatura en las termografías, como en el caso concreto de la Iglesia de San Juan Bautista en Monóvar (s. xviII) (Figuras 3 y 4).

Así, en la representación gráfica de la temperatura en distintos puntos de la citada cúpula de Monóvar (Figura 4) siguiendo una línea diagonal, se obtiene una parte central con menor transmisión de temperatura $\left(7,7^{\circ} \mathrm{C}\right)$ respecto a los extremos $\left(8,7^{\circ} \mathrm{C}\right)$. Dichos valores se corresponden con la diferencia de espesor en la cúpula, mayor en la fábrica de la zona más alta de la cúpula (temperaturas más bajas) y menor en la fábrica coincidiendo con los 2/3 inferiores (temperaturas más altas). La gráfica muestra una distribución en U donde los extremos sombreados en azul (correspondientes con la parte inferior de la cúpula) presentan una mayor transmisión de calor mientras que la parte central (correspondiente con la zona superior de la cúpula) muestra menor transmisión de calor; lo que confirma la diferencia entre el peralte interior y exterior existente.

Para la interpretación de las distintas termografías, la investigación también se ha apoyado en los distintos documentos disponibles de cada templo (croquis, puesta a escala y fuentes bibliográficas) y es interesante matizar que la comparación establecida entre flecha y diámetro de cada cúpula ha determinado un perfil medio de 0,58 para las cúpulas estudiadas, confirmando la existencia de peraltes en cúpulas apuntadas rebajadas; dicho valor se encuentra por debajo de la relación esbelta ideal, tanto por motivos estéticos como constructivos, fijada habitualmente en dos tercios del diámetro de la cúpula (14).También cabe destacar que, en el caso de existir una sola cáscara, la diferencia existente entre el peralte interior y el exterior en los templos se conseguía mediante un relleno de argamasa y cascotes en la parte superior de la cúpula, tal y como sucede en la Iglesia de la Virgen de los Dolores en el municipio de Dolores (Figura 5). De esta forma, la terminación exterior de la cúpula, con perfil apuntado, garantiza suficiente pendiente para las tejas de la zona superior, evitando la entrada de agua.
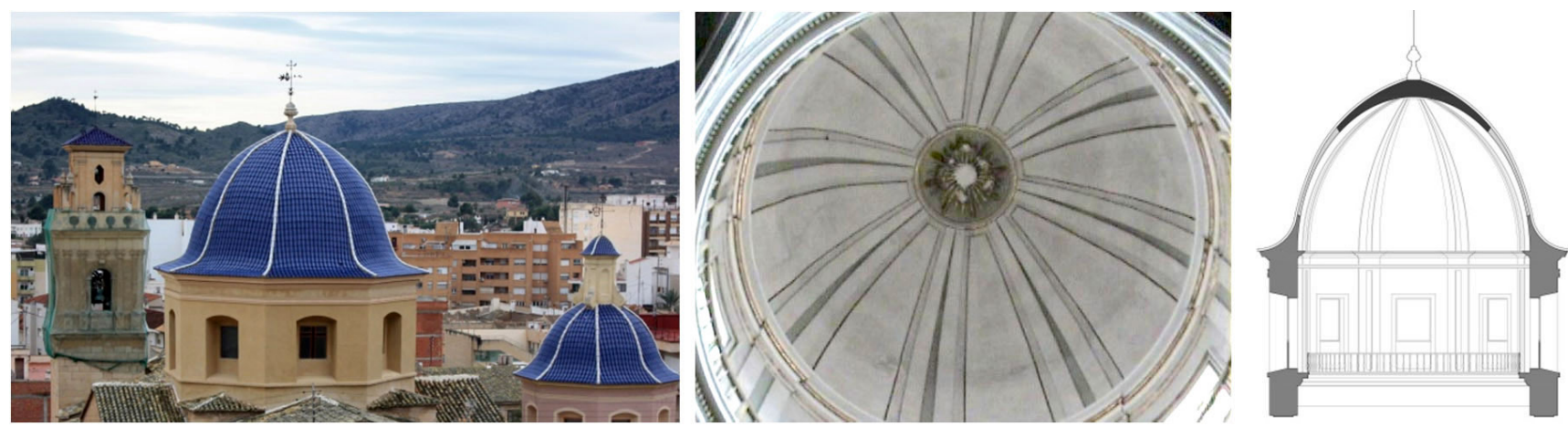

Figura 3. Cúpula de crucero en la Iglesia de San Juan Bautista en Monóvar. Imagen izquierda. Vista exterior de la cúpula. Imagen central. Vista interior de la cúpula. Imagen derecha. Sección donde se identifica la diferencia de perfiles interior y exterior en la cúpula peraltada. (Fuente propia).

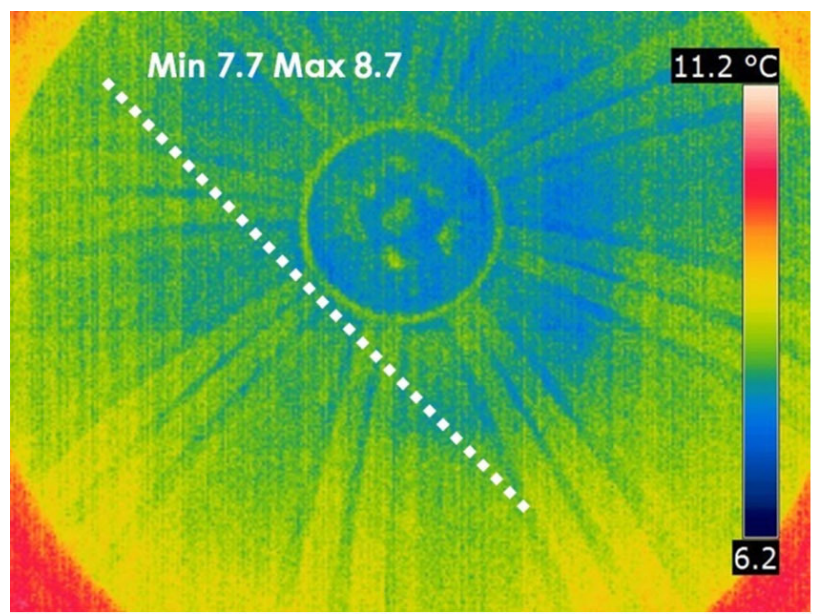

\section{Iglesia de San Juan Bautista en Monóvar}

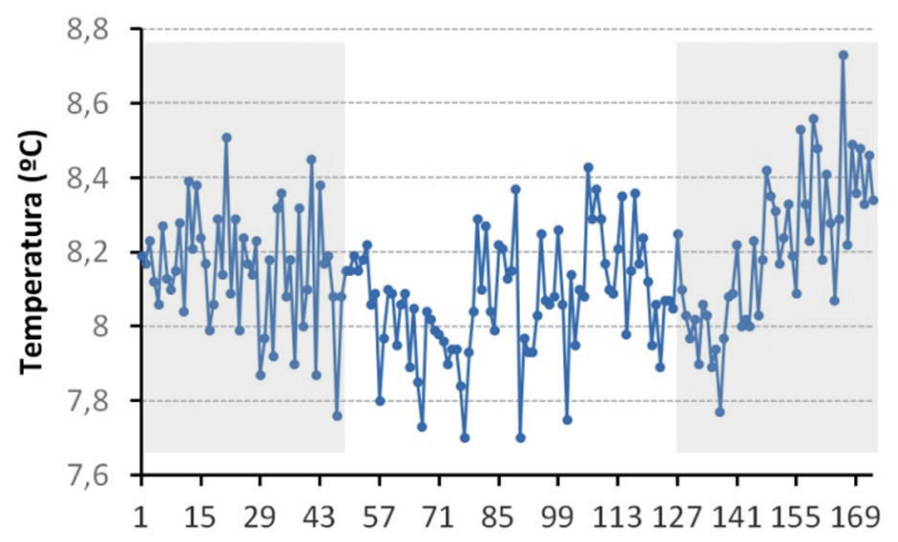

Figura 4. Imagen izquierda. Termografía de la cúpula de crucero en la Iglesia de San Juan Bautista en Monóvar con identificación de temperatura mínima $\left(7,7^{\circ} \mathrm{C}\right)$ y máxima $\left(8,7^{\circ} \mathrm{C}\right)$. Imagen derecha. Gráfica de distribución de temperaturas en la citada cúpula.

(Fuente propia). 




\section{Iglesia de la Virgen de los Dolores en Dolores}

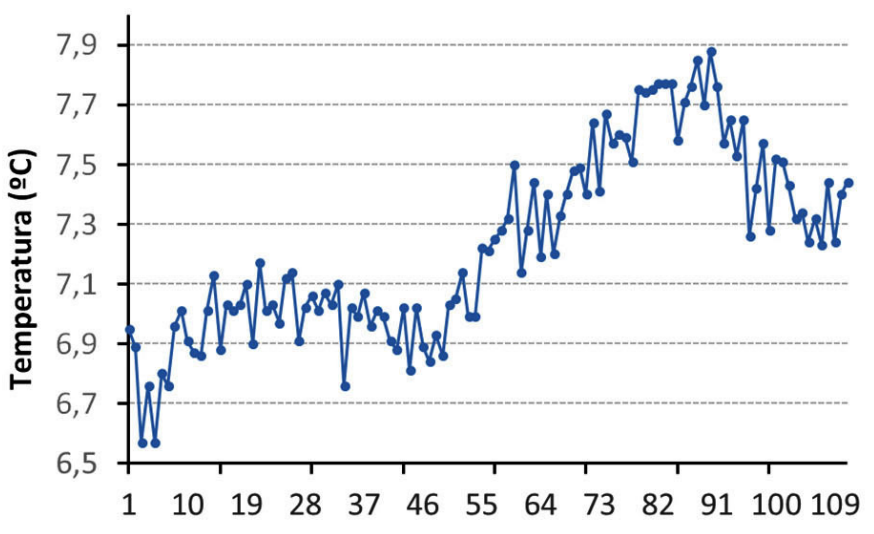

Figura 5. Imagen izquierda. Termografía de la cúpula de crucero en la Iglesia de la Virgen de los Dolores en el municipio de Dolores con identificación de temperatura mínima $\left(6,6^{\circ} \mathrm{C}\right)$ y máxima $\left(7,9^{\circ} \mathrm{C}\right)$. Imagen derecha. Gráfica de distribución de temperaturas en la citada cúpula. (Fuente propia).

Para la elaboración de la gráfica se ha evitado referenciar el punto central (pináculo) ya que, al elevarse sobre la cúpula y poseer una mayor superficie expuesta al sol, la incidencia directa en ese elemento es muy elevada, generando una mayor transmisión de temperatura.

En dichos casos, en las termografías obtenidas se observa la existencia de distintas zonas claramente identificadas en función del espesor de cada elemento. De esta forma, en la Figura 6 se aprecia cómo el arranque y la terminación de la cúpula presentan temperaturas más frías (menor transmisión de temperatura) correspondientes con un mayor espesor en las zonas de relleno, asegurando la evacuación del agua en la cubierta; por otra parte, la zona central aparece más caliente (mayor transmisión de temperatura) correspondiendo con un menor espesor donde no existen rellenos y la teja está próxima a la cáscara de ladrillo. La citada distribución de espesores corresponde con el perfil contracurvo característico en las cúpulas de la provincia de Alicante: aumenta en su base y bien se maciza el arranque o bien se colocan lengüetas de ladrillo perpendiculares a la cúpula para facilitar la evacuación a los faldones inferiores lejos de la fábrica principal; en ambos casos la distribución de la imagen térmica es similar.

\subsection{Caracterización de grietas o fisuras: estado de conservación}

Durante el estudio constructivo de las cúpulas se han identificado fisuras (afectan únicamente a la superficie del elemento o a su acabado) o grietas (afectan a todo el espesor del elemento) tanto horizontales como verticales de distinta índole y ubicación. La comparación de las imágenes termográficas obtenidas con las fotografías digitales tomadas in situ ha mostrado cómo dichas lesiones son, a veces, apreciables en las fotografías pero no en las termografías, mientras que en otros casos se observan en ambas.

Tras el análisis constructivo y termográfico para cada caso, se ha podido identificar cómo la aparición en la termografía del recorrido de una grieta implica un mayor alcance de la lesión, al existir un cambio de temperatura entre distintas zonas limítrofes; este cambio detectado supone una afección más intensa en el elemento constructivo, alcanzando capas más profundas o, incluso, llegando a atravesarlo. Por otra parte, la existencia de fisuras en los templos analizados afecta sólo al revestimiento interior de la cúpula y, al ser su inercia térmica prácticamente igual en las zonas fisuradas respecto a las no fisuradas, son prácticamente inapreciables en una imagen termográfica.

Un ejemplo destacable relacionado con este fenómeno es el caso del Santuario de la Virgen de Gracia en Biar (Figura 6), donde se aprecian grietas horizontales en la base de la cúpula coincidiendo con el principio y final de los huecos practicados en su cáscara (dintel y alféizar). Estas grietas son visibles tanto en las fotografías digitales como en las termografías, evidenciando la existencia de una discontinuidad significativa que provoca mayor transmisión de calor; si la discontinuidad no afectara a todo el espesor, no aparecería esa diferenciación de temperatura en la termografía.
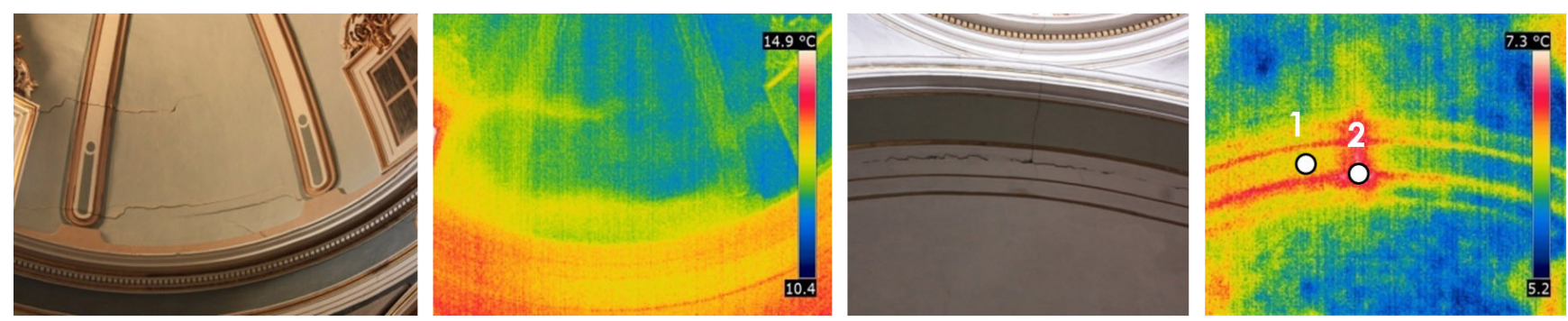

Figura 6. Magnitud de las lesiones existentes en el Santuario de la Virgen de Gracia en Biar. Imagen primera. Grietas en la cúpula del santuario. Imagen segunda. Termografía de la cúpula con fisuras de importancia leve. Imagen tercera. Grietas en la clave de los arcos torales. Imagen cuarta. Termografía de los arcos torales con grietas de mayor importancia. (Fuente propia). 
Sin embargo, en las inspecciones visuales y las fotografías obtenidas del citado santuario no sólo se observan grietas en la cúpula, sino también otros daños en sus elementos de sustento (por ejemplo en la clave de los arcos torales), construidos también con ladrillo. Así, y aunque en la fotografía digital se aprecie una fisura de poca magnitud, esta lesión se ve acentuada en la termografía, marcándose de manera considerable al existir una diferencia de temperatura de más de $1{ }^{\circ} \mathrm{C}$ entre la fisura y la inmediatez del arco; una diferencia que denota cómo dicha discontinuidad afecta a toda la dimensión del elemento.

\subsection{Reconocimiento de cúpulas restauradas: originales o rehabilitadas por completo}

En el apartado anterior se han identificado termográficamente aquellas fisuras que aparecen en las fotografías pero no en las imágenes térmicas, así como aquellas grietas que aparecen en ambas, siendo estas últimas más graves al afectar a todo el espesor de la fábrica. Sin embargo, otro caso diferente es aquel en que no se identifica ningún tipo de lesión en las fotografías y sí que aparecen en las termografías; en este caso ha de concluirse que la cúpula ha sido restaurada, y es posible distinguir si la restauración afecta sólo a su superficie (revestimiento interior) o si por el contrario afecta a la totalidad del elemento, dependiendo de la transmisión de temperatura detectada.

La Iglesia de San Juan Bautista de Cox (s. XviII) es un ejemplo de este último caso ya que, mientras en la inspección visual y las fotografías digitales de la cúpula no se detectan fisuras, en las termografías sí aparecen registradas ciertas discontinuidades (Figura 7). Así, se distinguen unas zonas en sentido radial con menor transmisión de temperatura que se corresponden con la existencia previa de fisuras en la cúpula, apareciendo dos densidades distintas y, por tanto, dos transmisiones de calor diferentes. Esta distribución térmica indica que la cúpula ha sido restaurada, a posteriori, con un material de construcción distinto al original.

Tras el estudio específico de documentación complementaria a las imágenes termográficas (15) se ha constatado la existencia de una importante rehabilitación en los años 90 de la iglesia de Cox para reparar las graves grietas meridianas presentes en la cúpula, derivadas de movimientos en sus estribos durante el terremoto de 1829 en la zona. En este caso, la existencia de linterna en el templo provocó que las grietas llegaran prácticamente hasta el arranque de la cúpula, haciendo imprescindible una consolidación estructural del elemento. Así, en primer lugar las grietas principales fueron rellenadas con mortero de reparación; posteriormente se ubicó, en el trasdos de la cúpula, una nueva cáscara de hormigón armado de unos $10 \mathrm{~cm}$ de espesor con armadura de reparto. Teniendo en cuenta estas consideraciones, es importante destacar las principales diferencias existentes entre las situaciones de las Figuras 7 y 8 ya que, mientras en la primera de ellas las fisuras aparecen a mayor temperatura que el resto de la cúpula (indicando que la intervención ha sido efectuada únicamente a nivel superficial), en la segunda las grietas aparecen a menor temperatura que el resto de la cúpula (al estar rellenas con mortero reparador de una densidad diferente a la del propio ladrillo).
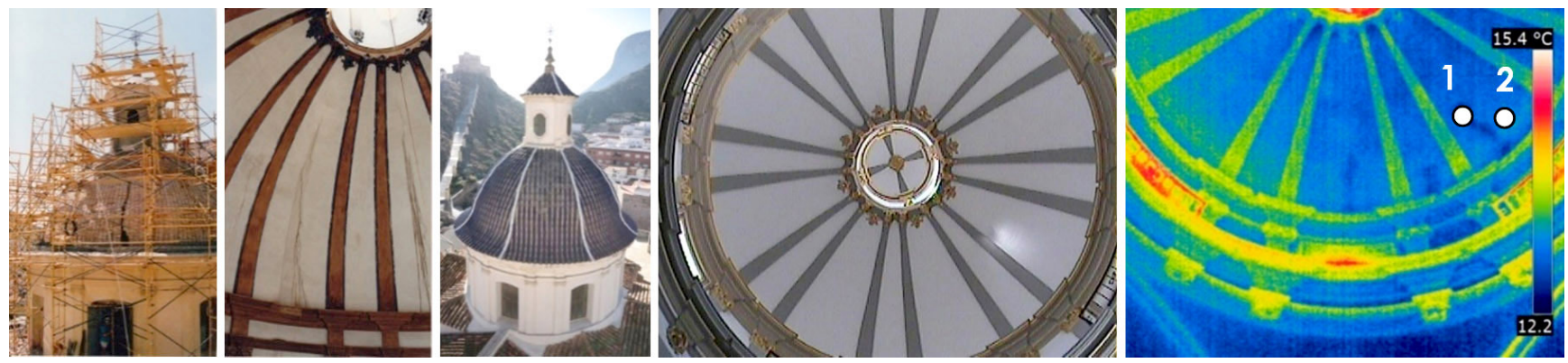

Figura 7. Imágenes de la Iglesia de San Juan Bautista de Cox en distintas épocas. Imagen primera. Grietas en la cúpula de la iglesia en el año 1990. Imagen segunda. Grietas de la citada cúpula tras la primera fase de restauración en los años 9o. Imagen tercera. Vista exterior de la cúpula actual. Imagen cuarta. Vista interior de la cúpula actual. Imagen quinta. Termografía de la cúpula con identificación de temperaturas destacadas Ta $1\left(12,7{ }^{\circ} \mathrm{C}\right)$ y Ta $2\left(13,2{ }^{\circ} \mathrm{C}\right)$. (Fuente imagen primera y segunda: Archivo Parroquial de San Juan Bautista de Cox. Fuente imagen tercera, cuarta y quinta: propia).
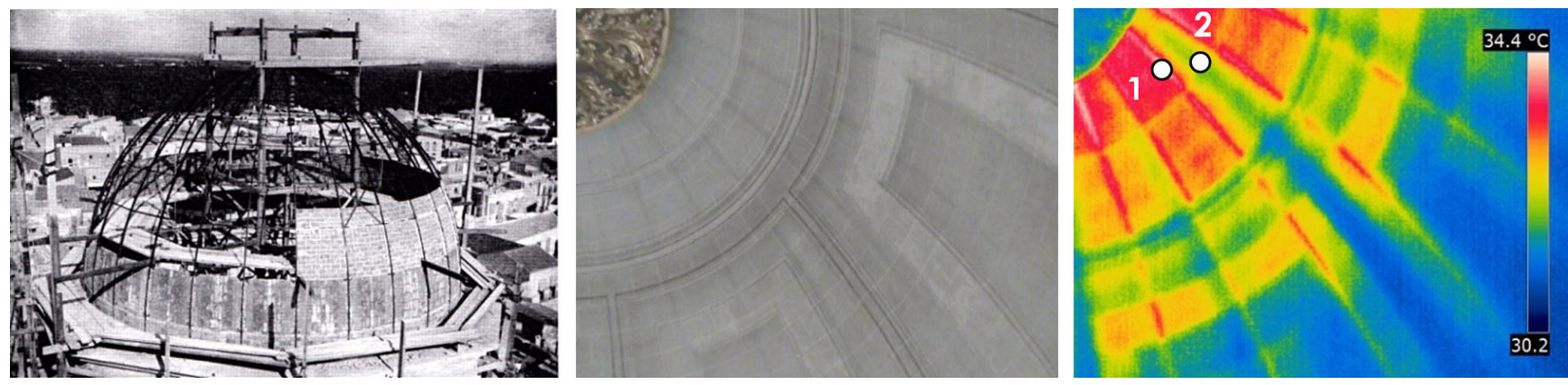

Figura 8. Imágenes de la Iglesia de Santa María de Elche. Imagen izquierda. Estructura metálica base para soportar la cúpula de ladrillo. Imagen central. Vista interior de la cúpula. Imagen derecha. Termografía de la cúpula con identificación de temperaturas destacadas $\mathrm{T}^{\mathrm{a}}{ }_{1}$ $\left(34,0^{\circ} \mathrm{C}\right)$ y T $2\left(32,0^{\circ} \mathrm{C}\right)$. (Fuente imagen izquierda: García Navarro et al. (13), p. 82. Fuente imagen central y derecha: propia). 
Tal y como se ha detallado en el ejemplo del templo de Cox, la termografía es una herramienta que puede ser utilizada para la identificación de restauraciones puntuales en cúpulas, determinando las zonas que han sido intervenidas. Asimismo, esta técnica también puede aplicarse para la caracterización de cúpulas completamente reconstruidas, como en el caso de la iglesia de Santa María de Elche (Figura 8) donde, a simple vista y en las imágenes convencionales, se aprecia la existencia de ciertas líneas en sentido radial que se marcan de manera más contundente en las termografías obtenidas. La distinta percepción de transmisión de calor que aparece en las imágenes térmicas hace intuir la existencia de distintos materiales en la cúpula, con un contraste de densidades bastante significativo, al presentar una serie de líneas muy marcadas en asintonía con las condiciones habitualmente observadas en otras cúpulas originales de la zona.

Por todo ello, y tras la consulta bibliográfica, se comprueba como desde 1745 existían distintos estudios oficiales que resaltaban el mal estado de conservación del templo (arcos, bóvedas y cúpulas estaban dañados) e incidían en la necesidad de intervención; aunque no es hasta principios del siglo xIX cuando se lleva a cabo una importante restauración, principalmente en la cúpula. Así, la cúpula original de piedra fue sustituida por una nueva de ladrillo en 1905 (Figura 8), solucionando los problemas que su empuje había producido sobre los elementos de sustento mediante el empleo de una armadura de hierro formada por 28 meridianos y 10 paralelos (14,54 m de diámetro) cubierta con cuatro capas de rasilla (10 $\mathrm{cm}$ de espesor aproximado) y 5.360 tejas planas; dando como resultado una nueva cúpula ligerísima, muy sólida y de aspecto similar a la antigua (16). Dicha estructura metálica auxiliar en forma de jaula semiesférica, soporte para las distintas capas de rasilla que componen la cubierta, se aprecia perfectamente en las termografías obtenidas al existir una discontinuidad entre los materiales utilizados, mostrando que dicha cúpula no es en absoluto original sino que se encuentra restaurada por completo. Además, en las imágenes digitales también se aprecia a simple vista la citada estructura metálica ubicada en el intradós de la cúpula, al estar recubierta únicamente por una capa interior de acabado de yeso imitando las molduras de piedra de la cúpula original.

\section{CONCLUSIONES}

La termografia es una técnica no destructiva habitualmente utilizada para la detección de anomalías y lesiones en edificación; sin embargo, su uso está hoy en día infravalorado como herramienta complementaria para el diagnóstico del estado de conservación en edificios históricos ya que permite identificar, tanto cualitativa como cuantitativamente, las singularidades constructivas de cada sistema mediante el análisis de los datos de transmisión térmica. De este modo, la utilización de la termografía infrarroja, junto con la puesta a escala de los croquis en cada edificio, la realización de dibujos en $3 \mathrm{D}$, la toma de fotografías digitales y el análisis de las fuentes documentales conservadas, han permitido profundizar en la identificación de los sistemas constructivos existentes en las cúpulas de los templos alicantinos desde finales del siglo XvII hasta principios del XIX, mostrando una visión particular de su estado específico de conservación y su originalidad, con viabilidad de generalización para otras tipologías constructivas.
Por otra parte, el uso de esta técnica de reconocimiento también ha permitido determinar distintas características de interés en dichas cúpulas como son los materiales originalmente empleados, la identificación de lesiones graves, moderadas o leves y la presencia de restauraciones anteriores; siendo todo ello posible durante las fases de análisis previas a la intervención en edificios históricos sin necesidad de métodos destructivos de inspección.

En resumen, tras el estudio termográfico llevado a cabo en el citado rango de 140 templos con cúpulas originales en la provincia de Alicante desde finales del siglo xvII hasta principios del xIx, cabe concluir:

\section{a) Detección de materiales y sistemas constructivos}

Teniendo en cuenta el contexto histórico-constructivo de los templos alicantinos, las termografías realizadas han permitido la identificación del material de construcción utilizado en sus cúpulas al contrastar los perfiles térmicos obtenidos con la fecha del propio edificio. Así, cabe destacar que las imágenes termográficas muestran cómo el ladrillo macizo (con dimensiones variables en función del caso) es utilizado de un modo mayoritario en los ejemplos estudiados (90,71 \%), destacando el escaso empleo de ladrillo hueco $(6,43 \%)$ o piedra $(2,86 \%)$ como material de construcción en los templos de la época.

\section{b) Detección de espesores}

Respecto a la determinación de espesores, las imágenes termográficas mayoritariamente muestran distribuciones donde la zona más alta ( $1 / 3$ del radio) presenta una menor transmisión de temperatura que la zona intermedia-baja $(2 / 3$ del radio). Esta disposición confirma la existencia de perfiles apuntados en los templos, con un peralte exterior mayor que el interior, que se traduce constructivamente en una variación del espesor en su cáscara que se ve claramente reflejada en las termografías obtenidas.

Así, al considerar las diferencias existentes entre el perfil interior y exterior de las cúpulas en los 140 templos estudiados, en un 75,71 \% de los casos las termografías muestran distribuciones con menor transmisión de temperatura en la parte más alta de la cúpula (1/3 del radio) y mayor transmisión en la zona intermedia-baja ( $2 / 3$ del radio), pudiendo catalogarse dichas cúpulas como apuntadas. Por el contrario, la distribución opuesta (mayor transmisión de temperatura en la parte más alta y menor en la zona intermedia-baja) ha permitido la identificación de cúpulas con perfil rebajado en el 6,43\% de los templos. La carencia de esa diferenciación en las termografías implica la existencia de un perfil semiesférico en la cúpula; lo que se observa en el 17,86 \% de los casos.

\section{c) Detección de grietas o fisuras}

En el estudio visual y constructivo de las cúpulas seleccionadas se han identificado fisuras y grietas, tanto horizontales como verticales, de distinta índole y ubicación. Tras el análisis termográfico realizado, es posible concluir que la aparición de grietas en la imagen térmica implica un mayor alcance de la lesión en el elemento constructivo, al existir una discontinuidad significativa que provoca mayor transmisión de calor; por otra parte, la existencia de fisuras superficiales no es apreciable térmicamente, al no afectar la disconti- 
nuidad a todo su espesor. Con ello, es posible establecer una primera aproximación sobre la importancia constructiva de dichas lesiones sin necesidad de plantear un ensayo destructivo en el elemento patrimonial.

\section{d) Detección de cúpulas originales}

En los casos en que visualmente no es posible la identificación de lesión alguna en los elementos constructivos, el empleo de la imagen termográfica ha permitido concluir si la cúpula ha sido restaurada, bien total o parcialmente, bien superficial o estructuralmente, dependiendo de la transmisión de temperatura detectada en cada caso.

Así, respecto a la identificación de la originalidad de las cúpulas estudiadas, las termografías obtenidas han mostrado que, considerando la selección final de cúpulas, 135 de ellas son cúpulas originales $(96,43 \%)$ en las que no se observa ningún tipo de restauración posterior a su época de construcción, mientras que las 5 restantes pueden catalogarse como res- tauradas (3,57 \%) al apreciarse cierto nivel de intervención, ya sea parcial o total.

Como conclusión final, cabe destacar que la presente investigación ha demostrado, en una aplicación concreta en las cúpulas de los templos alicantinos, cómo la termografía es una herramienta que ofrece una valiosa información adicional y complementaria a la consulta de fuentes bibliográficas o la toma de datos in situ desde la perspectiva de un estudio no destructivo. Este sistema de caracterización sencillo y económico, con facilidad de adaptación a cualquier otra edificación histórica, permite un análisis efectivo de los sistemas constructivos utilizados mediante unos datos hasta ahora infravalorados para el establecimiento de criterios de restauración, conservación y futura intervención en estas construcciones religiosas, siempre teniendo en cuenta que, en determinadas ocasiones que sea posible, el empleo de catas complementarias será un elemento más a considerar en el análisis de un determinado elemento, material o sistema constructivo.

\section{REFERENCIAS}

(1) Capitulos y Condiciones del arrendamiento de la obra de la torre. Documentos de la Iglesia de Catral, G29. (1744). Catral: Archivo Parroquial de los Santos Juanes de Catral.

(2) AENOR. (1987). UNE-EN-ISO 7345 Aislamiento térmico. Magnitudes físicas y definiciones. Madrid: Asociación Española de Normalización y Certificación (AENOR).

(3) Infrared Training Center. (2003). Manual Curso Termografía nivel I. Madrid: Infrared Training Center, Alava Ingenieros.

(4) AENOR. (2007). UNE-EN ISO 6946 Componentes y elementos para la edificación. Resistencia térmica y transmitancia térmica. Método de cálculo. Madrid: Asociación Española de Normalización y Certificación (AENOR).

(5) González Fernández, D. A. (2006). Contribuciones a las técnicas no destructivas para evaluación y prueba de procesos y materiales basadas en radiaciones infrarrojas (Tesis doctoral). Santander: Escuela Técnica Superior de Ingenieros Industriales y de Telecomunicación.

(6) Balaras, C. A., Argiriou, A. A. (2002). Infrared Thermography for Building Diagnostics. Elsevier Energy and Buildings, 34(2): 171-183, doi: http://dx.doi.org/10.1016/So378-7788(01)00105-0.

(7) Barreira, E., de Freitas, V. (2007). Evaluation of building materials using infrared thermography. Construction and Building Materials, 21(1): 218-224, doi: http://dx.doi.org/10.1016/j.conbuildmat.2005.06.049.

(8) Cañas Guerrero, I., Martín Ocaña, S., González Requena, I. (2003). Aplicabilidad de la termografía para la inspección de los edificios rurales: caso de una comarca española. Informes de la Construcción, 55(488): 21-28, doi: http://dx.doi. org/10.3989/ic.2003.v55.i488.538.

(9) García Jara, F. (2008). Las cúpulas de la arquitectura religiosa de la provincia de Alicante: del renacimiento al siglo XIX (Tesis doctoral). Valencia: Universidad Politécnica de Valencia.

(10) Expediente sobre los planes respectivos a la parroquial de Monóvar (1769). Monóvar: Archivo Parroquial de San Juan Bautista de Monóvar.

(11) Restauración de la cúpula de la iglesia de Santa María Magdalena. (2009). Tibi: Archivo Municipal de Tibi.

(12) Pérez Jiménez, R., Capell Bore, L. (1987). Proyecto de restauración y consolidación de la iglesia de San Pedro en Pinoso. Primera Fase. Proyecto de arquitectura.

(13) Pérez Sánchez, J. C., Piedecausa García, B. (2015). Cúpulas de crucero en templos de la provincia de Alicante (s.XviI-XIX): construcción y geometría. Informes de la Construcción, 67(538): e077, doi: http://dx.doi.org/10.3989/ic.13.176.

(14) Fornés y Gurrea, M. (1841). Observaciones sobre la práctica del arte de edificar. Valencia: Imprenta de Cabrerizo.

(15) Documentación de la Restauración de la iglesia. (1990). Archivo Parroquial de San Juan Bautista de Cox.

(16) García Navarro, J. J., Navarro Mallebrera, R., Serrano Bru, A. (2009). Las huellas del tiempo, construcción y restauración de la Basílica de Santa María. Elche: Gráficas Estilo. 